\title{
Common property (E.A) and existence of fixed points in Menger spaces
}

\author{
Sunny Chauhan ${ }^{1 *}$, Sumitra Dalal ${ }^{2}$, Wutiphol Sintunavarat ${ }^{3}$ and Jelena Vujaković ${ }^{4}$
}

"Correspondence: sun.gkv@gmail.com

${ }^{1}$ Near Nehru Training Centre, Nai Basti B-14, H. No. 274, Bijnor, Uttar Pradesh 246701, India Full list of author information is available at the end of the article

\begin{abstract}
The aim of this paper is to prove some common fixed-point theorems for weakly compatible mappings in Menger spaces satisfying common property (E.A). Some examples are also given which demonstrate the validity of our results. As an application of our main result, we present a common fixed-point theorem for four finite families of self-mappings in Menger spaces. Our result is an improved probabilistic version of the result of Sedghi et al. [Gen. Math. 18:3-12, 2010].
\end{abstract} MSC: 54H25; 47H10; 54E70

Keywords: t-norm; Menger space; weakly compatible mappings; property (E.A); common property (E.A)

\section{Introduction}

In 1922, Banach proved the principal contraction result [1]. As we know, there have been published many works about fixed-point theory for different kinds of contractions on some spaces such as quasi-metric spaces [2], cone metric spaces [3], convex metric spaces [4], partially ordered metric spaces [5-9], G-metric spaces [10-14], partial metric spaces [15, 16], quasi-partial metric spaces [17], fuzzy metric spaces [18], and Menger spaces [19]. Also, studies either on approximate fixed point or on qualitative aspects of numerical procedures for approximating fixed points are available in the literature; see $[4,20,21]$.

Jungck and Rhoades [22] weakened the notion of compatibility by introducing the notion of weakly compatible mappings (extended by Singh and Jain [23] to probabilistic metric space) and proved common fixed-point theorems without assuming continuity of the involved mappings in metric spaces. In 2002, Aamri and Moutawakil [24] introduced the notion of property (E.A) (extended by Kubiaczyk and Sharma [25] to probabilistic metric space) for self-mappings which contained the class of noncompatible mappings due to Pant [26]. Further, Liu et al. [27] defined the notion of common property (E.A) (extended by Ali et al. [28] to probabilistic metric space) which contains the property (E.A) and proved several fixed-point theorems under hybrid contractive conditions. Since then, there has been continuous and intense research activity in fixed-point theory and by now there exists an extensive literature (e.g. [29-33] and the references therein).

Many mathematicians proved several common fixed-point theorems for contraction mappings in Menger spaces by using different notions viz. compatible mappings, weakly compatible mappings, property (E.A), common property (E.A) (see [28, 34-51]).

02014 Chauhan et al: licensee Springer. This is an Open Access article distributed under the terms of the Creative Commons Attribution License (http://creativecommons.org/licenses/by/2.0), which permits unrestricted use, distribution, and reproduction in any medium, provided the original work is properly cited. 
In the present paper, we prove some common fixed-point theorems for weakly compatible mappings in Menger space using the common property (E.A). Some examples are also derived which demonstrate the validity of our results. As an application of our main result, we extend the related results to four finite families of self-mappings in Menger spaces.

\section{Preliminaries}

In the sequel, $\mathbb{R}, \mathbb{R}^{+}$, and $\mathbb{N}$ denote the set of real numbers, the set of nonnegative real numbers, and the set of positive integers, respectively.

Definition 2.1 [52] A triangular norm $*$ (shortly t-norm) is a binary operation on the unit interval $[0,1]$ such that for all $a, b, c, d \in[0,1]$ the following conditions are satisfied:

(1) $a * 1=a$,

(2) $a * b=b * a$,

(3) $a * b \leq c * d$ whenever $a \leq c$ and $b \leq d$,

(4) $a *(b * c)=(a * b) * c$.

Examples of t-norms are $a * b=\min \{a, b\}, a * b=a b$, and $a * b=\max \{a+b-1,0\}$.

Definition 2.2 [52] A mapping $F: \mathbb{R} \rightarrow \mathbb{R}^{+}$is called a distribution function if it is nondecreasing and left continuous with $\inf \{F(t): t \in \mathbb{R}\}=0$ and $\sup \{F(t): t \in \mathbb{R}\}=1$. We shall denote the set of all distribution functions on $(-\infty, \infty)$ by $\mathfrak{I}$, while $H$ will always denotes the specific distribution function defined by

$$
H(t)= \begin{cases}0, & \text { if } t \leq 0 \\ 1, & \text { if } t>0\end{cases}
$$

If $X$ is a nonempty set, $\mathcal{F}: X \times X \rightarrow \Im$ is called a probabilistic distance on $X$ and $F(x, y)$ is usually denoted by $F_{x, y}$.

Definition 2.3 [52] The ordered pair $(X, \mathcal{F})$ is called a probabilistic metric space (shortly, PM-space) if $X$ is a nonempty set and $\mathcal{F}$ is a probabilistic distance satisfying the following conditions:

(1) $F_{x, y}(t)=1$ for all $t>0$ if and only if $x=y$,

(2) $F_{x, y}(0)=0$ for all $x, y \in X$,

(3) $F_{x, y}(t)=F_{y, x}(t)$ for all $x, y \in X$ and for all $t>0$,

(4) $F_{x, z}(t)=1, F_{z, y}(s)=1 \Rightarrow F_{x, y}(t+s)=1$ for $x, y, z \in X$ and $t, s>0$.

Every metric space $(X, d)$ can always be realized as a probabilistic metric space defined by $F_{x, y}(t)=H(t-d(x, y))$ for all $x, y \in X$ and $t>0$. So probabilistic metric spaces offer a wider framework (than that of the metric spaces) and are general enough to cover even wider statistical situations.

Definition 2.4 [19] A Menger space $(X, \mathcal{F}, *)$ is a triplet where $(X, \mathcal{F})$ is a probabilistic metric space and $*$ is a t-norm satisfying the following condition:

$$
F_{x, y}(t+s) \geq F_{x, z}(t) * F_{z, y}(s),
$$

for all $x, y, z \in X$ and $t, s>0$. 
Throughout this paper, $(X, \mathcal{F}, *)$ is considered to be a Menger space with condition $\lim _{t \rightarrow \infty} \mathcal{F}_{x, y}(t)=1$ for all $x, y \in X$. Every fuzzy metric space $(X, M, *)$ may be a Menger space by considering $\mathcal{F}: X \times X \rightarrow \Im$ defined by $F_{x, y}(t)=M(x, y, t)$ for all $x, y \in X$.

Definition 2.5 [52] Let $(X, \mathcal{F}, *)$ be a Menger space and $*$ be a t-norm. Then

(1) a sequence $\left\{x_{n}\right\}$ in $X$ is said to converge to a point $x$ in $X$ if and only if for every $\epsilon>0$ and $\lambda \in(0,1)$, there exists an integer $N \in \mathbb{N}$ such that $F_{x_{n}, x}(\epsilon)>1-\lambda$ for all $n \geq N$;

(2) a sequence $\left\{x_{n}\right\}$ in $X$ is said to be Cauchy if for every $\epsilon>0$ and $\lambda \in(0,1)$, there exists an integer $N \in \mathbb{N}$ such that $F_{x_{n}, x_{m}}(\epsilon)>1-\lambda$ for all $n, m \geq N$.

A Menger space in which every Cauchy sequence is convergent is said to be complete.

Definition 2.6 [53] A pair $(A, S)$ of self-mappings of a Menger space $(X, \mathcal{F}, *)$ is said to be compatible if $\lim _{n \rightarrow \infty} F_{A S x_{n}, S A x_{n}}(t)=1$ for all $t>0$, whenever $\left\{x_{n}\right\}$ is a sequence in $X$ such that $\lim _{n \rightarrow \infty} A x_{n}=\lim _{n \rightarrow \infty} S x_{n}=z$ for some $z \in X$.

Definition 2.7 [28] A pair $(A, S)$ of self-mappings of a Menger space $(X, \mathcal{F}, *)$ is said to be noncompatible if there exists at least one sequence $\left\{x_{n}\right\}$ in $X$ such that $\lim _{n \rightarrow \infty} A x_{n}=z=$ $\lim _{n \rightarrow \infty} S x_{n}$ for some $z \in X$, but, for some $t>0$, either $\lim _{n \rightarrow \infty} F_{A S x_{n}, S A x_{n}}(t) \neq 1$ or the limit does not exist.

Definition 2.8 [25] A pair $(A, S)$ of self-mappings of a Menger space $(X, \mathcal{F}, *)$ is said to satisfy property (E.A) if there exists a sequence $\left\{x_{n}\right\}$ in $X$ such that

$$
\lim _{n \rightarrow \infty} A x_{n}=\lim _{n \rightarrow \infty} S x_{n}=z
$$

for some $z \in X$.

Remark 2.1 From Definition 2.8, it is easy to see that any two noncompatible selfmappings of $(X, \mathcal{F}, *)$ satisfy property (E.A) but the reverse need not be true (see [40, Example 1]).

Definition 2.9 [34] Two pairs $(A, S)$ and $(B, T)$ of self-mappings of a Menger space $(X, \mathcal{F}, *)$ are said to satisfy the common property (E.A) if there exist two sequences $\left\{x_{n}\right\}$, $\left\{y_{n}\right\}$ in $X$ such that

$$
\lim _{n \rightarrow \infty} A x_{n}=\lim _{n \rightarrow \infty} S x_{n}=\lim _{n \rightarrow \infty} B y_{n}=\lim _{n \rightarrow \infty} T y_{n}=z,
$$

for some $z \in X$.

Definition 2.10 [22] A pair $(A, S)$ of self-mappings of a nonempty set $X$ is said to be weakly compatible (or coincidentally commuting) if they commute at their coincidence points, i.e. if $A z=S z$ for some $z \in X$, then $A S z=S A z$.

Remark 2.2 If self-mappings $A$ and $S$ of a Menger space $(X, \mathcal{F}, *)$ are compatible then they are weakly compatible but the reverse need not be true (see [23, Example 1]). 
Remark 2.3 It is noticed that the notion of weak compatibility and the (E.A) property are independent to each other (see [54, Example 2.2]).

Definition 2.11 [41] Two families of self-mappings $\left\{A_{i}\right\}$ and $\left\{S_{j}\right\}$ are said to be pairwise commuting if:

(1) $A_{i} A_{j}=A_{j} A_{i}, i, j \in\{1,2, \ldots, m\}$,

(2) $S_{k} S_{l}=S_{l} S_{k}, k, l \in\{1,2, \ldots, n\}$,

(3) $A_{i} S_{k}=S_{k} A_{i}, i \in\{1,2, \ldots, m\}, k \in\{1,2, \ldots, n\}$.

\section{Main results}

Let $\Phi$ is a set of all increasing and continuous functions $\phi:(0,1] \rightarrow(0,1]$, such that $\phi(t)>t$ for every $t \in(0,1)$.

Example 3.1 Let $\phi:(0,1] \rightarrow(0,1]$ defined by $\phi(t)=t^{\frac{1}{2}}$. It is easy to see that $\phi \in \Phi$.

Before proving our main theorems, we begin with the following lemma.

Lemma 3.1 Let $A, B, S$ and $T$ be self-mappings of a Menger space $(X, \mathcal{F}, *)$, where $*$ is a continuous t-norm. Suppose that

(1) $A(X) \subset T(X)$ or $B(X) \subset S(X)$,

(2) the pair $(A, S)$ or $(B, T)$ satisfies property $(E . A)$,

(3) $B\left(y_{n}\right)$ converges for every sequence $\left\{y_{n}\right\}$ in $X$ whenever $T\left(y_{n}\right)$ converges or $A\left(x_{n}\right)$ converges for every sequence $\left\{x_{n}\right\}$ in $X$ whenever $S\left(x_{n}\right)$ converges,

(4) there exist $\phi \in \Phi$ and $1 \leq k<2$ such that

$$
F_{A x, B y}(t) \geq \phi\left(\min \left\{\begin{array}{c}
F_{S x, T y}(t), \\
\sup _{t_{1}+t_{2}=\frac{2}{k} t} \min \left\{F_{S x, A x}\left(t_{1}\right), F_{T y, B y}\left(t_{2}\right)\right\}, \\
\sup _{t_{3}+t_{4}=\frac{2}{k} t} \max \left\{F_{S x, B y}\left(t_{3}\right), F_{T y, A x}\left(t_{4}\right)\right\}
\end{array}\right\}\right)
$$

holds for all $x, y \in X, t>0$. Then the pairs $(A, S)$ and $(B, T)$ share the common property (E.A).

Proof Suppose the pair $(A, S)$ satisfies property (E.A), then there exists a sequence $\left\{x_{n}\right\}$ in $X$ such that

$$
\lim _{n \rightarrow \infty} A x_{n}=\lim _{n \rightarrow \infty} S x_{n}=z
$$

for some $z \in X$. Since $A(X) \subset T(X)$, hence for each $\left\{x_{n}\right\} \subset X$ there corresponds a sequence $\left\{y_{n}\right\} \subset X$ such that $A x_{n}=T y_{n}$. Therefore,

$$
\lim _{n \rightarrow \infty} T y_{n}=\lim _{n \rightarrow \infty} A x_{n}=z
$$

Thus in all, we have $A x_{n} \rightarrow z, S x_{n} \rightarrow z$ and $T y_{n} \rightarrow z$. By (3), the sequence $\left\{B y_{n}\right\}$ converges and in all we need to show that $B y_{n} \rightarrow z$ as $n \rightarrow \infty$. Let $B y_{n} \rightarrow l$ for $t>0$ as $n \rightarrow \infty$. Then, it is enough to show that $z=l$. Suppose that $z \neq l$, then there exists $t_{0}>0$ such that

$$
F_{z, l}\left(\frac{2}{k} t_{0}\right)>F_{z, l}\left(t_{0}\right)
$$


In order to establish the claim embodied in (3.4), let us assume that (3.4) does not hold. Then we have $\mathcal{F}_{z, l}\left(\frac{2}{k} t\right) \leq \mathcal{F}_{z, l}(t)$ for all $t>0$. Repeatedly using this equality, we obtain

$$
F_{z, l}(t) \geq F_{z, l}\left(\frac{2}{k} t\right) \geq \cdots \geq F_{z, l}\left(\left(\frac{2}{k}\right)^{n} t\right) \rightarrow 1,
$$

as $n \rightarrow \infty$. This shows that $F_{z, l}(t)=1$ for all $t>0$, which contradicts $z \neq l$, and hence (3.4) is proved. Using inequality (3.1), with $x=x_{n}, y=y_{n}$, we get

$$
\begin{aligned}
F_{A x_{n}, B y_{n}}\left(t_{0}\right) & \geq \phi\left(\min \left\{\begin{array}{c}
F_{S x_{n}, T y_{n}}\left(t_{0}\right), \\
\sup _{t_{1}+t_{2}=\frac{2}{k} t_{0}} \min \left\{F_{S x_{n}, A x_{n}}\left(t_{1}\right), F_{T y_{n}, B y_{n}}\left(t_{2}\right)\right\}, \\
\sup _{t_{3}+t_{4}=\frac{2}{k} t_{0}} \max \left\{F_{S x_{n}, B y_{n}}\left(t_{3}\right), F_{T y_{n}, A x_{n}}\left(t_{4}\right)\right\}
\end{array}\right\}\right) \\
& \geq \phi\left(\min \left\{\begin{array}{c}
F_{S x_{n}, T y_{n}}\left(t_{0}\right), \\
\min \left\{F_{S x_{n}, A x_{n}}(\epsilon), F_{T y_{n}, B y_{n}}\left(\frac{2}{k} t_{0}-\epsilon\right)\right\}, \\
\max \left\{F_{S x_{n}, B y_{n}}\left(\frac{2}{k} t_{0}-\epsilon\right), F_{T y_{n}, A x_{n}}(\epsilon)\right\}
\end{array}\right\}\right),
\end{aligned}
$$

for all $\epsilon \in\left(0, \frac{2}{k} t_{0}\right)$. As $n \rightarrow \infty$, it follows that

$$
\begin{aligned}
F_{z, l}\left(t_{0}\right) & \geq \phi\left(\min \left\{\begin{array}{c}
F_{z, z}\left(t_{0}\right), \\
\min \left\{F_{z, z}(\epsilon), F_{z, l}\left(\frac{2}{k} t_{0}-\epsilon\right)\right\}, \\
\max \left\{F_{z, l}\left(\frac{2}{k} t_{0}-\epsilon\right), F_{z, z}(\epsilon)\right\}
\end{array}\right\}\right) \\
& =\phi\left(F_{z, l}\left(\frac{2}{k} t_{0}-\epsilon\right)\right) \\
& >F_{z, l}\left(\frac{2}{k} t_{0}-\epsilon\right),
\end{aligned}
$$

as $\epsilon \rightarrow 0$, we have

$$
F_{z, l}\left(t_{0}\right) \geq F_{z, l}\left(\frac{2}{k} t_{0}\right)
$$

which contradicts (3.4). Therefore, $z=l$. Hence the pairs $(A, S)$ and $(B, T)$ share the common property (E.A).

Remark 3.1 In general, the converse of Lemma 3.1 is not true (see [28, Example 3.1]).

Now we prove a common fixed-point theorem for two pairs of mappings in Menger space which is an extension of the main result of Sedghi et al. [55] in a version of Menger space.

Theorem 3.1 Let A, B, S and T be self-mappings of a Menger space $(X, \mathcal{F}, *)$, where $*$ is a continuous t-norm satisfying inequality (3.1) of Lemma 3.1. Suppose that

(1) the pairs $(A, S)$ and $(B, T)$ share the common property (E.A),

(2) $S(X)$ and $T(X)$ are closed subsets of $X$.

Then the pairs $(A, S)$ and $(B, T)$ have a coincidence point each. Moreover, $A, B, S$, and $T$ have a unique common fixed point provided both pairs $(A, S)$ and $(B, T)$ are weakly compatible. 
Proof Since the pairs $(A, S)$ and $(B, T)$ share the common property (E.A), there exist two sequences $\left\{x_{n}\right\}$ and $\left\{y_{n}\right\}$ in $X$ such that

$$
\lim _{n \rightarrow \infty} A x_{n}=\lim _{n \rightarrow \infty} S x_{n}=\lim _{n \rightarrow \infty} B y_{n}=\lim _{n \rightarrow \infty} T y_{n}=z,
$$

for some $z \in X$. Since $S(X)$ is a closed subset of $X$, hence $\lim _{n \rightarrow \infty} S x_{n}=z \in S(X)$. Therefore, there exists a point $u \in X$ such that $S u=z$. Now we assert that $A u=S u$. Suppose that $A u \neq S u$, then there exists $t_{0}>0$ such that

$$
F_{A u, S u}\left(\frac{2}{k} t_{0}\right)>F_{A u, S u}\left(t_{0}\right) .
$$

In order to establish the claim embodied in (3.6), let us assume that (3.6) does not hold. Then we have $F_{A u, S u}\left(\frac{2}{k} t\right) \leq F_{A u, S u}(t)$ for all $t>0$. Repeatedly using this equality, we obtain

$$
F_{A u, S u}(t) \geq F_{A u, S u}\left(\frac{2}{k} t\right) \geq \cdots \geq F_{A u, S u}\left(\left(\frac{2}{k}\right)^{n} t\right) \rightarrow 1,
$$

as $n \rightarrow \infty$. This shows that $F_{A u, S u}(t)=1$ for all $t>0$, which contradicts $A u \neq S u$ and hence (3.6) is proved. Using inequality (3.1), with $x=u, y=y_{n}$, we get

$$
\begin{aligned}
F_{A u, B y_{n}}\left(t_{0}\right) \geq \phi\left(\min \left\{\begin{array}{c}
F_{S u, T y_{n}}\left(t_{0}\right), \\
\sup _{t_{1}+t_{2}=\frac{2}{k} t_{0}} \min \left\{F_{S u, A u}\left(t_{1}\right), F_{T y_{n}, B y_{n}}\left(t_{2}\right)\right\}, \\
\sup _{t_{3}+t_{4}=\frac{2}{k} t_{0}} \max \left\{F_{S u, B y_{n}}\left(t_{3}\right), F_{T y_{n}, A u}\left(t_{4}\right)\right\}
\end{array}\right\}\right) \\
\geq \phi\left(\min \left\{\begin{array}{c}
F_{z, T y_{n}}\left(t_{0}\right), \\
\min \left\{F_{z, A u}\left(\frac{2}{k} t_{0}-\epsilon\right), F_{B y_{n}, T y_{n}}(\epsilon)\right\}, \\
\max \left\{F_{z, B y_{n}}(\epsilon), F_{T y_{n}, z}\left(\frac{2}{k} t_{0}-\epsilon\right)\right\}
\end{array}\right\}\right),
\end{aligned}
$$

for all $\epsilon \in\left(0, \frac{2}{k} t_{0}\right)$. As $n \rightarrow \infty$, it follows that

$$
\begin{aligned}
F_{A u, z}\left(t_{0}\right) & \geq \phi\left(\min \left\{\begin{array}{c}
F_{z, z}\left(t_{0}\right), \\
\min \left\{F_{z, A u}\left(\frac{2}{k} t_{0}-\epsilon\right), F_{z, z}(\epsilon)\right\}, \\
\max \left\{F_{z, z}(\epsilon), F_{z, z}\left(\frac{2}{k} t_{0}-\epsilon\right)\right\}
\end{array}\right\}\right) \\
& =\phi\left(F_{z, A u}\left(\frac{2}{k} t_{0}-\epsilon\right)\right) \\
& >F_{A u, z}\left(\frac{2}{k} t_{0}-\epsilon\right),
\end{aligned}
$$

as $\epsilon \rightarrow 0$, we have

$$
F_{A u, z}\left(t_{0}\right) \geq F_{A u, z}\left(\frac{2}{k} t_{0}\right),
$$

which contradicts (3.6). Therefore $A u=S u=z$ and hence $u$ is a coincidence point of $(A, S)$. If $T(X)$ is a closed subset of $X$. Therefore there exists a point $v \in X$ such that $T v=z$. Now we assert that $B v=T v=z$. Let, on the contrary, $B v \neq T v$. As earlier, there exists $t_{0}>0$ such 
that

$$
F_{B v, T v}\left(\frac{2}{k} t_{0}\right)>F_{B v, T v}\left(t_{0}\right) .
$$

To support the claim, let it be untrue. Then we have $F_{B v, T v}\left(\frac{2}{k} t\right) \leq F_{B v, T v}(t)$ for all $t>0$. Repeatedly using this equality, we obtain

$$
F_{B v, T v}(t) \geq F_{B v, T v}\left(\frac{2}{k} t\right) \geq \cdots \geq F_{B v, T v}\left(\left(\frac{2}{k}\right)^{n} t\right) \rightarrow 1,
$$

as $n \rightarrow \infty$. This shows that $F_{B v, T v}(t)=1$ for all $t>0$, which contradicts $B v \neq T v$ and hence (3.7) is proved. Using inequality (3.1), with $x=x_{n}, y=v$, we get

$$
\begin{aligned}
F_{A x_{n}, B v}\left(t_{0}\right) & \geq \phi\left(\min \left\{\begin{array}{c}
F_{S x_{n}, T v}\left(t_{0}\right), \\
\sup _{t_{1}+t_{2}=\frac{2}{k} t_{0}} \min \left\{F_{S x_{n}, A x_{n}}\left(t_{1}\right), F_{T v, B v}\left(t_{2}\right)\right\}, \\
\sup _{t_{3}+t_{4}=\frac{2}{k} t_{0}} \max \left\{F_{S x_{n}, B v}\left(t_{3}\right), F_{T v, A x_{n}}\left(t_{4}\right)\right\}
\end{array}\right\}\right) \\
& \geq \phi\left(\min \left\{\begin{array}{r}
F_{S x_{n}, z}\left(t_{0}\right), \\
\min \left\{F_{S x_{n}, A x_{n}}(\epsilon), F_{z, B v}\left(\frac{2}{k} t_{0}-\epsilon\right)\right\}, \\
\max \left\{F_{S x_{n}, B v}\left(\frac{2}{k} t_{0}-\epsilon\right), F_{z, A x_{n}}(\epsilon)\right\}
\end{array}\right\}\right),
\end{aligned}
$$

for all $\epsilon \in\left(0, \frac{2}{k} t_{0}\right)$. As $n \rightarrow \infty$, it follows that

$$
\begin{aligned}
F_{z, B v}\left(t_{0}\right) & \geq \phi\left(\min \left\{\begin{array}{c}
F_{z, z}\left(t_{0}\right), \\
\min \left\{F_{z, z}(\epsilon), F_{z, B v}\left(\frac{2}{k} t_{0}-\epsilon\right)\right\}, \\
\max \left\{F_{z, B v}\left(\frac{2}{k} t_{0}-\epsilon\right), F_{z, z}(\epsilon)\right\}
\end{array}\right\}\right) \\
& =\phi\left(F_{z, B v}\left(\frac{2}{k} t_{0}-\epsilon\right)\right) \\
& >F_{z, B v}\left(\frac{2}{k} t_{0}-\epsilon\right),
\end{aligned}
$$

as $\epsilon \rightarrow 0$, we have

$$
F_{z, B v}\left(t_{0}\right) \geq F_{z, B v}\left(\frac{2}{k} t_{0}\right)
$$

which contradicts (3.7). Therefore $B v=T v=z$, which shows that $v$ is a coincidence point of the pair $(B, T)$.

Since the pair $(A, S)$ is weakly compatible, therefore $A z=A S u=S A u=S z$. Now we assert that $z$ is a common fixed point of $(A, S)$. If $z \neq A z$, then on using (3.1) with $x=z, y=v$, we get, for some $t_{0}>0$,

$$
\begin{gathered}
F_{A z, B v}\left(t_{0}\right) \geq \phi\left(\min \left\{\begin{array}{c}
F_{S z, T v}\left(t_{0}\right), \\
\sup _{t_{1}+t_{2}=\frac{2}{k} t_{0}} \min \left\{F_{S z, A z}\left(t_{1}\right), F_{T v, B v}\left(t_{2}\right)\right\}, \\
\sup _{t_{3}+t_{4}=\frac{2}{k} t_{0}} \max \left\{F_{S z, B v}\left(t_{3}\right), F_{T v, A z}\left(t_{4}\right)\right\}
\end{array}\right\}\right), \\
F_{A z, z}\left(t_{0}\right) \geq \phi\left(\min \left\{\begin{array}{c}
F_{A z, z}\left(t_{0}\right), \\
\min \left\{F_{A z, A z}(\epsilon), F_{z, z}\left(\frac{2}{k} t_{0}-\epsilon\right)\right\}, \\
\max \left\{F_{A z, z}(\epsilon), F_{z, A z}\left(\frac{2}{k} t_{0}-\epsilon\right)\right\}
\end{array}\right\}\right),
\end{gathered}
$$


for all $\epsilon \in\left(0, \frac{2}{k} t_{0}\right)$. As $\epsilon \rightarrow 0$, we have

$$
\begin{aligned}
F_{A z, z}\left(t_{0}\right) & \geq \phi\left(\min \left\{F_{A z, z}\left(t_{0}\right), F_{z, A z}\left(\frac{2}{k} t_{0}\right)\right\}\right) \\
& =\phi\left(F_{A z, z}\left(t_{0}\right)\right) \\
& >F_{A z, z}\left(t_{0}\right),
\end{aligned}
$$

which is a contradiction. Hence $A z=S z=z$, i.e. $z$ is a common fixed point of $(A, S)$. Also the pair $(B, T)$ is weakly compatible, therefore $B z=B T v=T B v=T z$. Now we show that $z$ is also a common fixed point of $(B, T)$. If $z \neq B z$, then on using (3.1) with $x=u, y=z$, we get, for some $t_{0}>0$,

$$
\begin{aligned}
& F_{A u, B z}\left(t_{0}\right) \geq \phi\left(\min \left\{\begin{array}{c}
F_{S u, T z}\left(t_{0}\right), \\
\sup _{t_{1}+t_{2}=\frac{2}{k} t_{0}} \min \left\{F_{S u, A u}\left(t_{1}\right), F_{T z, B z}\left(t_{2}\right)\right\}, \\
\sup _{t_{3}+t_{4}=\frac{2}{k} t_{0}} \max \left\{F_{S u, B z}\left(t_{3}\right), F_{T z, A u}\left(t_{4}\right)\right\}
\end{array}\right\}\right), \\
& F_{z, B z}\left(t_{0}\right) \geq \phi\left(\min \left\{\begin{array}{c}
F_{z, B z}\left(t_{0}\right), \\
\min \left\{F_{z, z}(\epsilon), F_{B z, B z}\left(\frac{2}{k} t_{0}-\epsilon\right)\right\}, \\
\max \left\{F_{z, B z}(\epsilon), F_{B z, z}\left(\frac{2}{k} t_{0}-\epsilon\right)\right\}
\end{array}\right\}\right),
\end{aligned}
$$

for all $\epsilon \in\left(0, \frac{2}{k} t_{0}\right)$. As $\epsilon \rightarrow 0$, we have

$$
\begin{aligned}
F_{z, B z}\left(t_{0}\right) & \geq \phi\left(\min \left\{F_{z, B z}\left(t_{0}\right), F_{B z, z}\left(\frac{2}{k} t_{0}\right)\right\}\right) \\
& =\phi\left(F_{z, B z}\left(t_{0}\right)\right) \\
& >F_{z, B z}\left(t_{0}\right),
\end{aligned}
$$

which is a contradiction. Therefore $B z=z=T z$, which shows that $z$ is a common fixed point of the pair $(B, T)$. Therefore $z$ is a common fixed point of both pairs $(A, S)$ and $(B, T)$. The uniqueness of common fixed point is an easy consequence of inequality (3.1).

Remark 3.2 Theorem 3.1 is an improved probabilistic version of the result of Sedghi et al. [55, Theorem 1] for two pairs of self-mappings without any requirement on containment of ranges amongst the involved mappings.

The following example illustrates Theorem 3.1.

Example 3.2 Let $(X, \mathcal{F}, *)$ be a Menger space, where $X=[2,19]$, with continuous t-norm $*$ is defined by $a * b=a b$ for all $a, b \in[0,1]$ and

$$
F_{x, y}(t)=\left(\frac{t}{t+1}\right)^{|x-y|}
$$


for all $x, y \in X$. The function $\phi$ is defined as in Example 3.1. Define the self-mappings $A, B$, $S$, and $T$ by

$$
\begin{aligned}
& A(x)=\left\{\begin{array}{ll}
2, & \text { if } x \in\{2\} \cup(3,19] ; \\
3, & \text { if } x \in(2,3],
\end{array} \quad B(x)= \begin{cases}2, & \text { if } x \in\{2\} \cup(3,19] ; \\
2.5, & \text { if } x \in(2,3],\end{cases} \right. \\
& S(x)=\left\{\begin{array}{ll}
2, & \text { if } x=2 ; \\
10, & \text { if } x \in(2,3] ; \\
\frac{x+77}{40}, & \text { if } x \in(3,19],
\end{array} \quad T(x)= \begin{cases}2, & \text { if } x=2 ; \\
13, & \text { if } x \in(2,3) ; \\
14, & \text { if } x=3 ; \\
\frac{x+77}{40}, & \text { if } x \in(3,19] .\end{cases} \right.
\end{aligned}
$$

We take $\left\{x_{n}\right\}=\left\{3+\frac{1}{n}\right\},\left\{y_{n}\right\}=\{2\}$ or $\left\{x_{n}\right\}=\{2\},\left\{y_{n}\right\}=\left\{3+\frac{1}{n}\right\}$. We have

$$
\lim _{n \rightarrow \infty} A x_{n}=\lim _{n \rightarrow \infty} S x_{n}=\lim _{n \rightarrow \infty} B y_{n}=\lim _{n \rightarrow \infty} T y_{n}=2 \in X .
$$

Therefore, both pairs $(A, S)$ and $(B, T)$ satisfy the common property (E.A).

It is noted that $A(X)=\{2,3\} \nsubseteq[2,2.4] \cup\{13,14\}=T(X)$ and $B(X)=\{2,2.5\} \nsubseteq[2,2.4] \cup$ $\{10\}=S(X)$. On the other hand, $S(X)$ and $T(X)$ are closed subsets of $X$. Thus, all the conditions of Theorem 3.1 are satisfied and 2 is a unique common fixed point of the pairs $(A, S)$ and $(B, T)$, which also remains a point of coincidence as well. Also, all the involved mappings are even discontinuous at their unique common fixed point 2.

Remark 3.3 In fact, the mapping $\mathcal{F}$ in Example 3.2 is also a fuzzy metric. However, the result of Sedghi et al. [55, Theorem 1] cannot be used for this case since $A(X) \nsubseteq T(X)$ and $B(X) \nsubseteq S(X)$.

Theorem 3.2 The conclusion of Theorem 3.1 remains true if the condition (2) of Theorem 3.1 is replaced by the following:

$(2)^{\prime} \overline{A(X)} \subset T(X)$ and $\overline{B(X)} \subset S(X)$, where $\overline{A(X)}$ is the closure range of $A$ and $\overline{B(X)}$ is the closure range of $B$.

Proof Since the pairs $(A, S)$ and $(B, T)$ satisfy the common property (E.A), there exist two sequences $\left\{x_{n}\right\}$ and $\left\{y_{n}\right\}$ in $X$ such that

$$
\lim _{n \rightarrow \infty} A x_{n}=\lim _{n \rightarrow \infty} S x_{n}=\lim _{n \rightarrow \infty} B y_{n}=\lim _{n \rightarrow \infty} T y_{n}=z
$$

for some $z \in X$. Then since $z \in \overline{A(X)}$ and $\overline{A(X)} \subset T(X)$ there exists a point $v \in X$ such that $z=T v$. By the proof of Theorem 3.1, we can show that the pair $(B, T)$ has a coincidence point, call it v, i.e. $B v=T v$. Since $z \in \overline{B(X)}$ and $\overline{B(X)} \subset S(X)$ there exists a point $u \in X$ such that $z=S u$. Similarly we can also prove that the pair $(A, S)$ has a coincidence point, call it $u$, i.e. $A u=S u$. The rest of the proof is on the lines of the proof of Theorem 3.1, hence it is omitted.

Corollary 3.1 The conclusions of Theorems 3.1-3.2 remain true if condition (2) of Theorem 3.1 and condition (2)' of Theorem 3.2 are replaced by the following:

$(2)^{\prime \prime} A(X)$ and $B(X)$ are closed subsets of $X$ provided $A(X) \subset T(X)$ and $B(X) \subset S(X)$. 
Theorem 3.3 Let $(X, \mathcal{F}, *)$ be a Menger space, where $*$ is a continuous $t$-norm. Let $A, B$, $S$ and $T$ be mappings from $X$ into itself and satisfying the conditions (1)-(4) of Lemma 3.1. Suppose that

(5) $S(X)($ or $T(X))$ is a closed subset of $X$.

Then the pairs $(A, S)$ and $(B, T)$ have a coincidence point each. Moreover, $A, B, S$ and $T$ have a unique common fixed point provided both pairs $(A, S)$ and $(B, T)$ are weakly compatible.

Proof In view of Lemma 3.1, the pairs $(A, S)$ and $(B, T)$ share the common property (E.A), i.e. there exist two sequences $\left\{x_{n}\right\}$ and $\left\{y_{n}\right\}$ in $X$ such that

$$
\lim _{n \rightarrow \infty} A x_{n}=\lim _{n \rightarrow \infty} S x_{n}=\lim _{n \rightarrow \infty} B y_{n}=\lim _{n \rightarrow \infty} T y_{n}=z
$$

for some $z \in X$.

If $S(X)$ is a closed subset of $X$, then on the lines of Theorem 3.1, we can show that the pair $(A, S)$ has coincidence point, say $u$, i.e. $A u=S u=z$. Since $A(X) \subset T(X)$ and $A u \in A(X)$, there exists $v \in X$ such that $A u=T v$. The rest of the proof runs along the lines of the proof of Theorem 3.1, therefore details are omitted.

Remark 3.4 Theorem 3.3 is also a partial improvement of Theorem 3.1 besides relaxing the closedness of one of the subspaces.

Example 3.3 In setting of Example 3.2, replace the self-mappings $A, B, S$ and $T$ by

$$
\begin{aligned}
& A(x)=\left\{\begin{array}{ll}
2, & \text { if } x \in\{2\} \cup(3,19] ; \\
3, & \text { if } x \in(2,3],
\end{array} \quad B(x)= \begin{cases}2, & \text { if } x \in\{2\} \cup(3,19] ; \\
4, & \text { if } x \in(2,3],\end{cases} \right. \\
& S(x)=\left\{\begin{array}{ll}
2, & \text { if } x=2 ; \\
14, & \text { if } x \in(2,3] ; \\
\frac{x+1}{2}, & \text { if } x \in(3,19],
\end{array} \quad T(x)= \begin{cases}2, & \text { if } x=2 ; \\
11+x, & \text { if } x \in(2,3] ; \\
\frac{x+1}{2}, & \text { if } x \in(3,19] .\end{cases} \right.
\end{aligned}
$$

It is noted that $A(X)=\{2,3\} \subset[2,10] \cup(13,14]=T(X)$ and $B(X)=\{2,4\} \subset[2,10] \cup\{14\}=$ $S(X)$. Also the pairs $(A, S)$ and $(B, T)$ commute at 2 which is their common coincidence point. Thus all the conditions of Theorems 3.2-3.3 and Corollary 3.1 are satisfied and 2 is a unique common fixed point of $A, B, S$ and $T$. Here, it may be pointed out that Theorem 3.1 is not applicable to this example as $S(X)$ is not a closed subset of $X$. Also, notice that some mappings in this example are even discontinuous at their unique common fixed point 2.

By choosing $A, B, S$, and $T$ suitably, we can drive a multitude of common fixed-point theorems for a pair or triod of self-mappings. If we take $A=B$ and $S=T$ in Theorem 3.1 then we get the following natural result which is an improved probabilistic version of the result of Sedghi et al. [55, Theorem 1].

Corollary 3.2 Let $(X, \mathcal{F}, *)$ be a Menger space, where $*$ is a continuous $t$-norm. Let $A$ and $S$ be mappings from $X$ into itself and satisfying the following conditions:

(1) The pair $(A, S)$ shares property (E.A),

(2) $S(X)$ is a closed subset of $X$, 
(3) there exist $\phi \in \Phi$ and $1 \leq k<2$ such that

$$
F_{A x, A y}(t) \geq \phi\left(\min \left\{\begin{array}{c}
F_{S x, S y}(t), \\
\sup _{t_{1}+t_{2}=\frac{2}{k} t} \min \left\{F_{S x, A x}\left(t_{1}\right), F_{S y, A y}\left(t_{2}\right)\right\}, \\
\sup _{t_{3}+t_{4}=\frac{2}{k} t} \max \left\{F_{S x, A y}\left(t_{3}\right), F_{S y, A x}\left(t_{4}\right)\right\}
\end{array}\right\}\right)
$$

holds for all $x, y \in X$ and $t>0$. Then the pair $(A, S)$ has a coincidence point. Moreover, $A$ and $S$ have a unique common fixed point provided the pair $(A, S)$ is weakly compatible.

Our next theorem is proved for six self-mappings in Menger space, which extends earlier proved Theorem 3.1.

Theorem 3.4 Let $(X, \mathcal{F}, *)$ be a Menger space, where $*$ is a continuous $t$-norm. Let $A, B$, $R, S, H$ and $T$ be mappings from $X$ into itself and satisfying the following conditions:

(1) The pairs $(A, S R)$ and $(B, T H)$ share the common property (E.A),

(2) $S R(X)$ and $T H(X)$ are closed subsets of $X$,

(3) there exist $\phi \in \Phi$ and $1 \leq k<2$ such that

$$
F_{A x, B y}(t) \geq \phi\left(\min \left\{\begin{array}{c}
F_{S R x, T H y}(t), \\
\sup _{t_{1}+t_{2}=\frac{2}{k} t} \min \left\{F_{S R x, A x}\left(t_{1}\right), F_{T H y, B y}\left(t_{2}\right)\right\}, \\
\sup _{t_{3}+t_{4}=\frac{2}{k} t} \max \left\{F_{S R x, B y}\left(t_{3}\right), F_{T H y, A x}\left(t_{4}\right)\right\}
\end{array}\right\}\right)
$$

holds for all $x, y \in X$ and $t>0$. Then the pairs $(A, S R)$ and $(B, T H)$ have a coincidence point each. Moreover, $A, B, R, S, H$, and $T$ have a unique common fixed point provided the pairs $(A, S R)$ and $(B, T H)$ commute pairwise (i.e. $A S=S A, A R=R A, S R=R S, B T=T B, B H=H B$, and $T H=H T)$.

Proof By Theorem 3.1, $A, B$, TH and $S R$ have a unique common fixed point $z$ in $X$. We show that $z$ is a unique common fixed point of the self-mappings $A, R$ and $S$. If $z \neq R z$, then on using (3.9) with $x=R z, y=z$, we get, for some $t_{0}>0$,

$$
\begin{aligned}
& F_{A(R z), B z}\left(t_{0}\right) \geq \phi\left(\min \left\{\begin{array}{c}
F_{S R(R z), T H z}\left(t_{0}\right), \\
\sup _{t_{1}+t_{2}=\frac{2}{k} t_{0}} \min \left\{F_{S R(R z), A(R z)}\left(t_{1}\right), F_{T H z, B z}\left(t_{2}\right)\right\}, \\
\sup _{t_{3}+t_{4}=\frac{2}{k} t_{0}} \max \left\{F_{S R(R z), B z}\left(t_{3}\right), F_{T H z, A(R z)}\left(t_{4}\right)\right\}
\end{array}\right\}\right), \\
& F_{R z, z}\left(t_{0}\right) \geq \phi\left(\min \left\{\begin{array}{c}
F_{R z, z}\left(t_{0}\right), \\
\min \left\{F_{R z, R z}(\epsilon), F_{z, z}\left(\frac{2}{k} t_{0}-\epsilon\right)\right\}, \\
\max \left\{F_{R z, z}(\epsilon), F_{z, R z}\left(\frac{2}{k} t_{0}-\epsilon\right)\right\}
\end{array}\right\}\right),
\end{aligned}
$$

for all $\epsilon \in\left(0, \frac{2}{k} t_{0}\right)$. As $\epsilon \rightarrow 0$, we have

$$
\begin{aligned}
F_{R z, z}\left(t_{0}\right) & \geq \phi\left(\min \left\{F_{R z, z}\left(t_{0}\right), F_{z, R z}\left(\frac{2}{k} t_{0}-\epsilon\right)\right\}\right) \\
& =\phi\left(F_{R z, z}\left(t_{0}\right)\right) \\
& >F_{R z, z}\left(t_{0}\right),
\end{aligned}
$$


which is a contradiction. Therefore, $R z=z$ and so $S(R z)=S(z)=z$. Similarly, we get $T z=$ $H z=z$. Hence $z$ is a unique common fixed point of self-mappings $A, B, R, S, H$ and $T$ in $X$.

Corollary 3.3 Let $(X, \mathcal{F}, *)$ be a Menger space, where $*$ is a continuous t-norm. Let $\left\{A_{i}\right\}_{i=1}^{m},\left\{B_{r}\right\}_{r=1}^{n},\left\{S_{k}\right\}_{k=1}^{p}$ and $\left\{T_{g}\right\}_{g=1}^{q}$ be four finite families from $X$ into itself such that $A=A_{1} A_{2} \cdots A_{m}, B=B_{1} B_{2} \cdots B_{n}, S=S_{1} S_{2} \cdots S_{p}$ and $T=T_{1} T_{2} \cdots T_{q}$, which satisfy the inequality (3.1). If the pairs $(A, S)$ and $(B, T)$ share the common property (E.A) along with closedness of $S(X)$ and $T(X)$, then $(A, S)$ and $(B, T)$ have a point of coincidence each.

Moreover, $\left\{A_{i}\right\}_{i=1}^{m},\left\{B_{r}\right\}_{r=1}^{n},\left\{S_{k}\right\}_{k=1}^{p}$ and $\left\{T_{g}\right\}_{g=1}^{q}$ have a unique common fixed point provided the pairs of families $\left(\left\{A_{i}\right\},\left\{S_{k}\right\}\right)$ and $\left(\left\{B_{r}\right\},\left\{T_{g}\right\}\right)$ are commute pairwise, where $i \in$ $\{1,2, \ldots, m\}, k \in\{1,2, \ldots, p\}, r \in\{1,2, \ldots, n\}$ and $g \in\{1,2, \ldots, q\}$.

Proof The proof of this theorem is similar to that of Theorem 3.1 contained in Imdad et al. [41], hence details are omitted.

Remark 3.5 Corollary 3.3 extends the result of Sedghi et al. [55, Theorem 2] to four finite families of self-mappings.

By setting $A_{1}=A_{2}=\cdots=A_{m}=A, B_{1}=B_{2}=\cdots=B_{n}=B, S_{1}=S_{2}=\cdots=S_{p}=S$, and $T_{1}=T_{2}=\cdots=T_{q}=T$ in Corollary 3.3, we deduce the following.

Corollary 3.4 Let $(X, \mathcal{F}, *)$ be a Menger space, where $*$ is a continuous $t$-norm. Let $A, B$, $S$ and $T$ be mappings from $X$ into itself such that the pairs $\left(A^{m}, S^{p}\right)$ and $\left(B^{n}, T^{q}\right)$ share the common property (E.A). Then there exist $\phi \in \Phi, 1 \leq k<2$ and $m, n, p, q \in \mathbb{N}$ such that

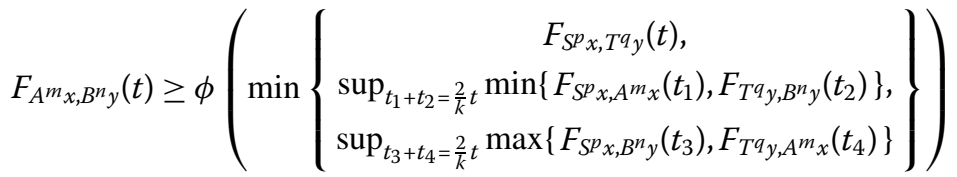

holds for all $x, y \in X$ and $t>0$. If $S^{p}(X)$ and $T^{q}(X)$ are closed subsets of $X$, then the pairs $(A, S)$ and $(B, T)$ have a point of coincidence each. Further, $A, B, S$, and $T$ have a unique common fixed point provided both pairs $\left(A^{m}, S^{p}\right)$ and $\left(B^{n}, T^{q}\right)$ commute pairwise.

\section{Conclusion}

Theorem 3.1 is proved for two pairs of weakly compatible mappings in Menger spaces using common property (E.A). Theorem 3.1 is an improved probabilistic version of the result of Sedghi et al. [55, Theorem 1] for two pairs of mappings without any requirement on containment of ranges amongst the involved mappings. Several results (Theorem 3.2, Theorem 3.3 and Corollary 3.1) are also defined for the existence of fixed points in Menger spaces. Example 3.2 and Example 3.3 are furnished in support of our results. As an extension of our main result, Theorem 3.4 is proved for six self-mappings using the notion of pairwise commuting whereas Corollary 3.3 extends Theorem 3.1 to four finite families of self-mappings. 
Authors' contributions

All authors read and approved the final manuscript.

\section{Author details}

${ }^{1}$ Near Nehru Training Centre, Nai Basti B-14, H. No. 274, Bijnor, Uttar Pradesh 246701, India. ${ }^{2}$ Department of Mathematics, Jazan University, Jazan, Kingdom of Saudi Arabia. ${ }^{3}$ Department of Mathematics and Statistics, Faculty of Science and Technology, Thammasat University Rangsit Center, Pathumthani, 12121, Thailand. ${ }^{4}$ Faculty of Sciences and Mathematics, Lole Ribara 29, Kosovska Mitrovica, 38 200, Serbia.

\section{Acknowledgements}

The authors would like to thank the referees for their useful comments on the manuscript.

\section{Received: 30 October 2013 Accepted: 6 January 2014 Published: 04 Feb 2014}

\section{References}

1. Banach, S: Sur les operations dans les ensembles abstraits et leur application aux equations integrales. Fundam. Math. 3, 133-181 (1922)

2. Hicks, TL: Fixed point theorems for quasi-metric spaces. Math. Jpn. 33(2), 231-236 (1988)

3. Choudhury, BS, Metiya, N: Coincidence point and fixed point theorems in ordered cone metric spaces. J. Adv. Math. Stud. 5(2), 20-31 (2012)

4. Olatinwo, MO, Postolache, M: Stability results for Jungck-type iterative processes in convex metric spaces. Appl. Math Comput. 218(12), 6727-6732 (2012)

5. Aydi, H, Karapınar, E, Postolache, M: Tripled coincidence point theorems for weak $\varphi$-contractions in partially ordered metric spaces. Fixed Point Theory Appl. 2012, 44 (2012)

6. Aydi, H, Shatanawi, W, Postolache, M, Mustafa, Z, Tahat, N: Theorems for Boyd-Wong type contractions in ordered metric spaces. Abstr. Appl. Anal. 2012, Article ID 359054 (2012)

7. Chandok, S, Postolache, M: Fixed point theorem for weakly Chatterjea-type cyclic contractions. Fixed Point Theory Appl. 2013, 28 (2013)

8. Choudhury, BS, Metiya, N, Postolache, M: A generalized weak contraction principle with applications to coupled coincidence point problems. Fixed Point Theory Appl. 2013, 152 (2013)

9. Shatanawi, W, Postolache, M: Common fixed point results of mappings for nonlinear contractions of cyclic form in ordered metric spaces. Fixed Point Theory Appl. 2013, 60 (2013)

10. Aydi, H, Postolache, M, Shatanawi, W: Coupled fixed point results for $(\psi, \phi)$-weakly contractive mappings in ordered G-metric spaces. Comput. Math. Appl. 63(1), 298-309 (2012)

11. Chandok, S, Mustafa, Z, Postolache, M: Coupled common fixed point theorems for mixed $g$-monotone mappings in partially ordered G-metric spaces. U. Politeh. Buch. Ser. A 75(4), 11-24 (2013)

12. Shatanawi, W, Pitea, A: Fixed and coupled fixed point theorems of omega-distance for nonlinear contraction. Fixed Point Theory Appl. 2013, 275 (2013)

13. Shatanawi, W, Postolache, M: Some fixed point results for a G-weak contraction in G-metric spaces. Abstr. Appl. Anal. 2012, Article ID 815870 (2012)

14. Shatanawi, W, Pitea, A: Omega-distance and coupled fixed point in G-metric spaces. Fixed Point Theory Appl. 2013, 208 (2013)

15. Aydi, H: Fixed point results for weakly contractive mappings in ordered partial metric spaces. J. Adv. Math. Stud. 4(2), 1-12 (2011)

16. Shatanawi, W, Postolache, M: Coincidence and fixed point results for generalized weak contractions in the sense of Berinde on partial metric spaces. Fixed Point Theory Appl. 2013, 54 (2013)

17. Shatanawi, W, Pitea, A: Some coupled fixed point theorems in quasi-partial metric spaces. Fixed Point Theory Appl. 2013, $153(2013)$

18. Grabiec, M: Fixed points in fuzzy metric spaces. Fuzzy Sets Syst. 27, 385-389 (1988)

19. Menger, K: Statistical metrics. Proc. Natl. Acad. Sci. USA 28, 535-537 (1942)

20. Haghi, RH, Postolache, M, Rezapour, S: On $T$-stability of the Picard iteration for generalized $\varphi$-contraction mappings. Abstr. Appl. Anal. 2012, Article ID 658971 (2012)

21. Miandaragh, MA, Postolache, M, Rezapour, S: Some approximate fixed point results for generalized $\alpha$-contractive mappings. U. Politeh. Buch. Ser. A 75(2), 3-10 (2013)

22. Jungck, G, Rhoades, BE: Fixed points for set valued functions without continuity. Indian J. Pure Appl. Math. 29(3), 227-238 (1998) MR1617919

23. Singh, B, Jain, S: A fixed point theorem in Menger space through weak compatibility. J. Math. Anal. Appl. 301(2), 439-448 (2005)

24. Aamri, M, Moutawakil, DEl: Some new common fixed point theorems under strict contractive conditions. J. Math. Anal. Appl. 270(1), 181-188 (2002)

25. Kubiaczyk, I, Sharma, S: Some common fixed point theorems in Menger space under strict contractive conditions. Southeast Asian Bull. Math. 32(1), 117-124 (2008) MR2385106 Zbl 1199.54223

26. Pant, RP: Common fixed point theorems for contractive maps. J. Math. Anal. Appl. 226, 251-258 (1998) MR1646430

27. Liu, Y, Wu, J, Li, Z: Common fixed points of single-valued and multi-valued maps. Int. J. Math. Math. Sci. 19, 3045-3055 (2005)

28. Ali, J, Imdad, M, Bahuguna, D: Common fixed point theorems in Menger spaces with common property (E.A) Comput. Math. Appl. 60(12), 3152-3159 (2010) MR2739482 (2011g:47124) Zbl 1207.54050

29. Abbas, M, Nazir, T, Radenović, S: Common fixed point of power contraction mappings satisfying (E.A) property in generalized metric spaces. Appl. Math. Comput. 219, 7663-7670 (2013)

30. Cakić, N, Kadelburg, Z, Radenović, S, Razani, A: Common fixed point results in cone metric spaces for a family of weakly compatible maps. Adv. Appl. Math. Sci. 1(1), 183-201 (2009)

31. Janković, S, Golubović, Z, Radenović, S: Compatible and weakly compatible mappings in cone metric spaces. Math. Comput. Model. 52, 1728-1738 (2010) 
32. Kadelburg, Z, Radenović, S, Rosić, B: Strict contractive conditions and common fixed point theorems in cone metric spaces. Fixed Point Theory Appl. 2009, Article ID 173838 (2009)

33. Long, W, Abbas, M, Nazir, T, Radenović, S: Common fixed point for two pairs of mappings satisfying (E.A) property in generalized metric spaces. Abstr. Appl. Anal. 2012, Article ID 394830 (2012)

34. Ali, J, Imdad, M, Miheț, D, Tanveer, M: Common fixed points of strict contractions in Menger spaces. Acta Math. Hung 132(4), 367-386 (2011)

35. Altun, I, Tanveer, M, Miheţ, D, Imdad, M: Common fixed point theorems of integral type in Menger PM spaces. J. Nonlinear Anal. Optim., Theory Appl. 3(1), 55-66 (2012)

36. Beg, I, Abbas, M: Common fixed points of weakly compatible and noncommuting mappings in Menger spaces. Int. J. Mod. Math. 3(3), 261-269 (2008)

37. Chauhan, S, Pant, BD: Common fixed point theorem for weakly compatible mappings in Menger space. J. Adv. Res. Pure Math. 3(2), 107-119(2011)

38. Cho, YJ, Park, KS, Park, WT, Kim, JK: Coincidence point theorems in probabilistic metric spaces. Kobe J. Math. 8(2), 119-131 (1991)

39. Fang, JX: Common fixed point theorems of compatible and weakly compatible maps in Menger spaces. Nonlinear Anal. 71(5-6), 1833-1843 (2009)

40. Fang, JX, Gao, Y: Common fixed point theorems under strict contractive conditions in Menger spaces. Nonlinear Anal. 70(1), 184-193 (2009)

41. Imdad, M, Ali, J, Tanveer, M: Coincidence and common fixed point theorems for nonlinear contractions in Menger PM spaces. Chaos Solitons Fractals 42(5), $3121-3129$ (2009) MR2562820 (2010j:54064) Zbl 1198.54076

42. Imdad, M, Tanveer, M, Hassan, M: Some common fixed point theorems in Menger PM spaces. Fixed Point Theory Appl. 2010, Article ID 819269 (2010)

43. Kumar, S, Chauhan, S, Pant, BD: Common fixed point theorem for noncompatible maps in probabilistic metric space. Surv. Math. Appl. (in press)

44. Kumar, S, Pant, BD: Common fixed point theorems in probabilistic metric spaces using implicit relation and property (E.A). Bull. Allahabad Math. Soc. 25(2), 223-235 (2010)

45. Kutukcu, S: A fixed point theorem in Menger spaces. Int. Math. Forum 1(32), 1543-1554 (2006)

46. Miheț, D: A note on a common fixed point theorem in probabilistic metric spaces. Acta Math. Hung. 125(1-2), 127-130 (2009)

47. O'Regan, D, Saadati, R: Nonlinear contraction theorems in probabilistic spaces. Appl. Math. Comput. 195(1), 86-93 (2008) MR2379198 Zbl 1135.54315

48. Pant, BD, Abbas, M, Chauhan, S: Coincidences and common fixed points of weakly compatible mappings in Menger spaces. J. Indian Math. Soc. 80(1-2), 127-139 (2013)

49. Pant, BD, Chauhan, S: A contraction theorem in Menger space. Tamkang J. Math. 42(1), 59-68 (2011) MR2815806 Zbl 1217.54053

50. Pant, BD, Chauhan, S: Common fixed point theorems for two pairs of weakly compatible mappings in Menger spaces and fuzzy metric spaces. Sci. Stud. Res. Ser. Math. Inform. 21(2), 81-96 (2011)

51. Saadati, R, O'Regan, D, Vaezpour, SM, Kim, JK: Generalized distance and common fixed point theorems in Menger probabilistic metric spaces. Bull. Iran. Math. Soc. 35(2), 97-117 (2009)

52. Schweizer, B, Sklar, A: Statistical metric spaces. Pac. J. Math. 10, 313-334 (1960)

53. Mishra, SN: Common fixed points of compatible mappings in PM-spaces. Math. Jpn. 36(2), $283-289$ (1991)

54. Pathak, HK, López, RR, Verma, RK: A common fixed point theorem using implicit relation and property (E.A) in metric spaces. Filomat 21(2), 211-234 (2007)

55. Sedghi, S, Shobe, N, Aliouche, A: A common fixed point theorem for weakly compatible mappings in fuzzy metric spaces. Gen. Math. 18(3), 3-12 (2010)

\section{Submit your manuscript to a SpringerOpen ${ }^{0}$ journal and benefit from:}

- Convenient online submission

Rigorous peer review

- Immediate publication on acceptance

- Open access: articles freely available online

- High visibility within the field

- Retaining the copyright to your article 